\title{
Incidence, clinical characteristics, risk factors and outcomes of meningoencephalitis in patients with COVID-19
}

\author{
Marcos Fragiel $^{1}$ • Òscar Miró ${ }^{2} \cdot$ Pere Llorens $^{3} \cdot$ Sònia Jiménez $^{2} \cdot$ Pascual Piñera Salmerón $^{4} \cdot$ Guillermo Burillo-Putze $^{5}$. \\ Alfonso Martín ${ }^{6}$ • Francisco Javier Martín-Sánchez ${ }^{1}$ • Eric Jorge García Lamberechts ${ }^{1}$ - Javier Jacob ${ }^{7}$.

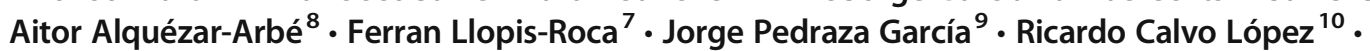 \\ María Teresa Maza Vera ${ }^{11}$. Francisco Javier Lucas-Imbernón ${ }^{12}$ • Félix González Martinez ${ }^{13} \cdot$ Ricardo Juárez $^{14}$. \\ Marcos Expósito Rodriguez ${ }^{5}$. Beatriz Maria Martinez Bautista ${ }^{15}$ - Ana Patricia Niembro Valdés ${ }^{16}$. \\ Jose Andres Sanchez Nicolas ${ }^{4}$. José María Ferreras Amez ${ }^{17}$. Jesús Porta-Etessam ${ }^{18}$ • Elpidio Calvo ${ }^{19}$. \\ Juan González del Castillo ${ }^{1}$ (D) - on behalf of the Spanish Investigators on Emergency Situations TeAm (SIESTA) network
}

Received: 29 August 2020 / Accepted: 17 February 2021 / Published online: 9 March 2021

(C) The Author(s), under exclusive licence to Springer-Verlag GmbH Germany, part of Springer Nature 2021

\begin{abstract}
We investigated the incidence, clinical characteristics, risk factors, and outcome of meningoencephalitis (ME) in patients with COVID-19 attending emergency departments (ED), before hospitalization. We retrospectively reviewed all COVID patients diagnosed with ME in 61 Spanish EDs (20\% of Spanish EDs, COVID-ME) during the COVID pandemic. We formed two control groups: non-COVID patients with ME (non-COVID-ME) and COVID patients without ME (COVID-non-ME). Unadjusted comparisons between cases and controls were performed regarding 57 baseline and clinical characteristics and 4 outcomes. Cerebrospinal fluid (CSF) biochemical and serologic findings of COVID-ME and non-COVID-ME were also investigated. We identified $29 \mathrm{ME}$ in 71,904 patients with COVID-19 attending EDs $(0.40 \%, 95 \% \mathrm{CI}=0.27-0.58)$. This incidence was higher than that observed in non-COVID patients $(150 / 1,358,134,0.11 \%$, 95\% CI=0.09-0.13; OR=3.65, 95\%CI=2.45-5.44). With respect to non-COVID-ME, COVID-ME more frequently had dyspnea and chest X-ray abnormalities, and neck stiffness was less frequent $(\mathrm{OR}=0.3,95 \% \mathrm{CI}=0.1-0.9)$. In $69.0 \%$ of COVID-ME, CSF cells were predominantly lymphocytes, and SARS$\mathrm{CoV}-2$ antigen was detected by RT-PCR in 1 patient. The clinical characteristics associated with a higher risk of presenting ME in COVID patients were vomiting $(\mathrm{OR}=3.7,95 \% \mathrm{CI}=1.4-10.2)$, headache $(\mathrm{OR}=24.7,95 \% \mathrm{CI}=10.2-60.1)$, and altered mental status
\end{abstract}

Juan González del Castillo

jgonzalezcast@gmail.com

1 Emergency Department, Hospital Clínico San Carlos, IDISSC, Univesidad Complutense, Profesor Martín Lagos s/n, 28040 Marid, Spain

2 Emergency Department, Hospital Clínic, IDIBAPS, University of Barcelona, Barcelona, Catalonia, Spain

3 Emergency Department, Hospital General de Alicante, University Miguel Hernández, Elche, Alicante, Spain

4 Emergency Department, Hospital Reina Sofía, Murcia, Spain

5 Emergency Department, Hospital Universitario de Canarias, Tenerife, Spain

6 Emergency Department, Hospital Severo Ochoa, Leganés, Madrid, Spain

7 Emergency Department, Hospital Universitari de Bellvitge, Barcelona, Catalonia, Spain

8 Emergency Department, Hospital de la Santa Creu i Sant Pau, Barcelona, Catalonia, Spain
9 Emergency Department, Hospital Valle de los Pedroches de Pozoblanco (Córdoba), Pozoblanco, Spain

10 Complejo Hospitalario Universitario de A Coruña, A Coruña, Spain

11 Complejo Hospitalario Universitario de Vigo, Hospital Álvaro Cunqueiro, Vigo, Spain

12 Hospital Universitario General de Albacete, Albacete, Spain

13 Hospital Virgen de la Luz (Cuenca), Cuenca, Spain

14 Emergency Department, Hospital Nuestra Señora del Prado de Talavera de la Reina (Toledo), Talavera de la Reina, Spain

15 Hospital Universitario Central Asturias, Oviedo, Spain

16 Hospital Universitario de Cabueñes (Gijón), Gijón, Spain

17 Hospital Clínico Universitario Lozano Blesa, Zaragoza, Spain

18 Neurology Department, Hospital Clínico San Carlos, Madrid, Spain

19 Internal Medicine Department, Hospital Clínico San Carlos, IDISSC, Universidad Complutense, Madrid, Spain 
$(\mathrm{OR}=12.9,95 \% \mathrm{CI}=6.6-25.0)$. COVID-ME patients had a higher in-hospital mortality than non-COVID-ME patients (OR=2.26; $95 \% \mathrm{CI}=1.04-4.48)$, and a higher need for hospitalization $(\mathrm{OR}=8.02 ; 95 \% \mathrm{CI}=1.19-66.7)$ and intensive care admission $(\mathrm{OR}=5.89 ; 95 \% \mathrm{CI}=3.12-11.14)$ than COVID-non-ME patients. ME is an unusual form of COVID presentation ( $<0.5 \%$ o cases $)$, but is more than 4-fold more frequent than in non-COVID patients attending the ED. As the majority of these MEs had lymphocytic predominance and in one patient SARS-CoV-2 antigen was detected in CSF, SARS-CoV-2 could be the cause of most of the cases observed. COVID-ME patients had a higher unadjusted in-hospital mortality than non-COVID-ME patients.

Keywords Meningoencephalitis $\cdot$ COVID-19 $\cdot$ SARS-Cov-2 $\cdot$ Incidence $\cdot$ Clinical characteristics $\cdot$ Risk factors $\cdot$ Outcome

\section{Introduction}

Coronavirus disease 2019 (COVID-19), caused by severe acute respiratory syndrome coronavirus 2 (SARS-CoV-2), is predominantly characterized by lower respiratory tract and cardiovascular system involvement. However, possible neurological symptoms have been described, such as headache, dizziness, hypogeusia, or neuralgia, even in up to $36.4 \%$ of the patients [1]. Nevertheless, the symptoms described are common in many infections and could represent disturbances in neurological function rather than neurological disease. Anosmia and ageusia have received much attention, but are ubiquitous in other common upper respiratory tract infections [2]. Some neurological complications of COVID-19, including meningoencephalitis (ME), have been previously described as case reports [3-5].

Connections between viral infections and central nervous system (CNS) pathologies are not new. Coronaviruses are not a common cause of neurological disease, but members of coronaviridae have already demonstrated the ability to produce neurological symptoms, including brain inflammation and encephalomyelitis, as well as presumed parainfectious disorders [2, 6-9]. Detection of SARS-CoV RNA in the CSF of a patient with SARS has been reported [10]. However, the pathophysiological mechanism of illness and the relationship between COVID-19 and CNS involvement remain unclear. The relative expression of the two key coreceptors for SARS-CoV-2 entry, ACE2, and TMPRSS2 has been described across multiple tissues and highlights that there is minimal expression in brain tissue, suggesting that direct brain infection would not be a common phenomenon. The one brain cell type, which does express both genes, is the oligodendrocyte, and therefore, SARS-CoV-2 encephalitis, when present, might be expected to be a predominantly white matter disease [2]. Experimental and clinical studies suggest brainstem involvement and the potential for transneuronal virus transmission in addition to misdirected host immune responses [11].

The real incidence of ME in patients with COVID-19 is currently unknown. There are some sporadically reported cases in patients with COVID-19 [3-5]. In order to further investigate these aspects, we designed the present study with the following specific objectives: (1) to determine the frequency of ME patients with COVID-19; (2) to describe whether there is any distinctive clinical characteristic in these patients in comparison with ME observed in non-COVID patients; (3) to uncover risk factors associated with the development of ME in patients with COVID-19; and (4) to investigate the outcomes of COVID patients presenting ME.

\section{Methods}

\section{Study design and setting}

The present study forms part of the Unusual Manifestations of Covid-19 (UMC-19) project, which was designed to investigate the potential relationship between COVID-19 and 10 different entities that could be influenced by SARS-Cov-2 infection itself: Guillain-Barre syndrome, spontaneous pneumothorax, acute pancreatitis, meningoencephalitis, (myo)pericarditis, acute coronary syndrome, deep venous thrombosis, pulmonary embolism, ictus, and gastrointestinal bleeding. The main objectives of the UMC-19 project were common for all entities, and consisted in the description of incidence, risk factors, clinical characteristics, and outcomes for each particular entity, using as comparators COVID patients that did not develop this entity as well as non-COVID patients that did present the entity. Details of the project have been extensively presented elsewhere [12].

In Spain, the first case of SARS-Cov-2 infection was detected on January $31^{\text {st }}, 2020$, and, accordingly, the definition of the COVID period for patient inclusion in the present study was set from March $1^{\text {st }}$ to April $30^{\text {th }}, 2020$ [13]. During this 61-day period, 213,435 cases of COVID-19 were confirmed in Spain by the Ministry of Health [14]. For the recruitment of controls, the UMC-19 project selected patients from two different periods: one corresponding to the same dates as the cases (from March $1^{\text {st }}$ to April $30^{\text {th }}, 2020$ ) and one corresponding to same period of the previous year (from March $1^{\text {st }}$ to April $30^{\text {th }}, 2019$ ).

The investigators of the UMC-19 project initially contacted 152 Spanish EDs, which roughly constitute half of the 312 hospital EDs of the Spanish public health network. Of these, 81 were interested in participating and analyzed the protocol, and finally 61 (20\% of Spanish EDs) consented to participate 
and sent all the required data in due time (Fig. 1). Altogether these 61 hospitals provide health coverage to 15.2 million citizens (32\% of the population of 46.9 million of Spain) and make up a balanced representation of the Spanish territory (representing 12 of the 17 Spanish autonomous communities), type of hospital (community, reference, and high-technology university hospitals were included), and involvement in pandemic (with EDs attending from 1 to $47 \%$ of the ED census during the COVID outbreak period corresponding to COVID patients) [12].

The investigation of ME in COVID patients, one of the entities included in the UMC-19 project, was labeled as UMC-19 Study 3 (UMC-19-S 3 ) and consisted in a retrospective, multicenter, case-control study that reviewed the medical reports of COVID patients who attended at Spanish EDs and who were diagnosed as having ME during ED assessment and management, before hospitalization.

\section{Cases of the UMC-19-S}

The case group was formed by COVID patients diagnosed with ME made on the basis of clinical presentation, lumbar puncture, abnormality on electroencephalography, and CT scan. All meningoencephalitis cases fulfill the consensus definition of encephalitis by the International Encephalitis Consortium [15], and other etiologies were rule out. As we wanted to investigate the role of SARS-CoV-19 in such unusual manifestations, before the patient was hospitalized and treatment with specific drugs had been initiated, the possible meningoencephalitis cases diagnosed during hospitalization were excluded. On the other hand, due to the shortage in all kind of diagnostic tests during the pandemic outbreak, diagnosis of COVID was accepted based on SARS-Cov-2 RNA detection in a nasopharyngeal swab by reverse transcriptase polymerase chain reaction (RT-PCR), a clinically compatible clinical picture, or the presence of the typical lung parenchymal infiltrates in chest X-ray or pulmonary $\mathrm{CT}$ in patients with some clinical symptoms attributable to COVID. Diagnostic adjudication was made by the principal investigator of each center, without external review.

\section{Controls of the UMC-19-S}

We defined two different control groups. One group was formed by all non-COVID patients with a diagnosis of ME attending the ED during the same period as the cases (March $1^{\text {st }}$ to April $30^{\text {th }}, 2020$ ), which was defined in the same terms as cases. In order to avoid that some of these control cases could eventually have inadvertent infection by SARSCov-2, in this group, we also included all patients with ME diagnosed in the ED from March $1^{\text {st }}$ to April $30^{\text {th }}, 2019$, just 1 year before the COVID pandemic. This group, named non-
Fig. 1 Study design and inclusion flow chart

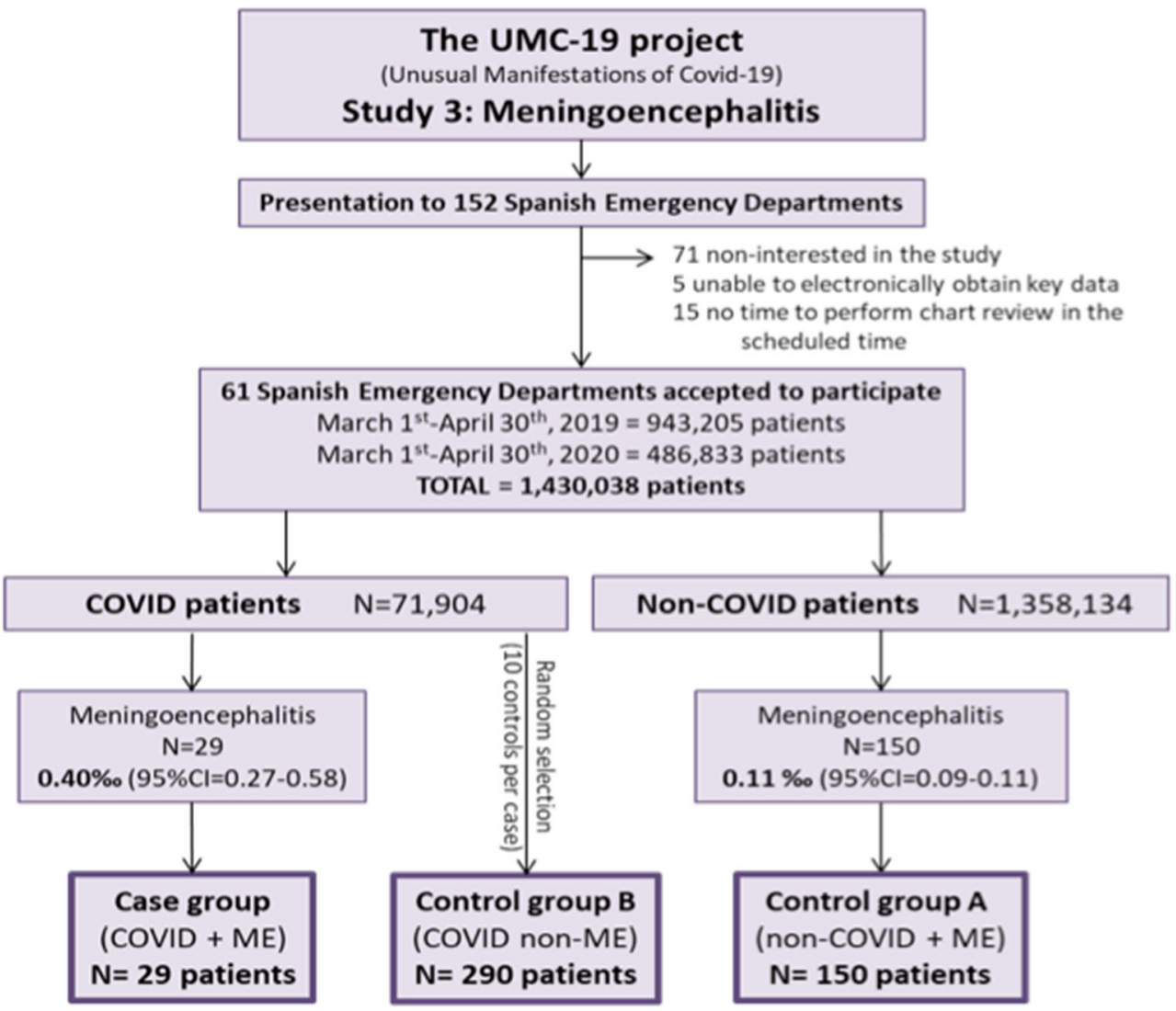


COVID-ME (control group A), was specifically designed to uncover the particular distinctive clinical characteristics of ME developed in COVID patients with respect to ME developed in the general population.

The second control group was formed by COVID patients (without ME) attending the ED during the same period of the COVID outbreak used for case inclusion (March $1^{\text {st }}$ to April $30^{\text {th }}, 2020$ ). This group was formed by selecting 10 COVID patients for every case detected by each center. Selection was randomly performed by the inclusion of the $5+5$ COVID patients seen immediately before and after each case included by the center. This group, named COVID-non-ME (control group B), was specifically designed to determine the risk factors for ME development in COVID patients.

\section{Independent variables}

We collected 57 independent variables, which included 2 demographic data (age, sex), 12 comorbidities (chronic obstructive pulmonary disease, asthma, active smoker, hypertension, dyslipidemia, diabetes mellitus, coronary artery disease, obesity - clinically estimated, cerebrovascular disease, chronic kidney disease - creatinine $>2 \mathrm{mg} /$ $\mathrm{dL}$, dementia, active cancer), 26 signs and symptoms recorded at ED arrival (time elapsed since symptoms started to ED attendance, fever, rhinorrhea, cough, expectoration, dyspnea, chest pain, abdominal pain, vomiting, diarrhea, altered mental status, headache, anosmia, dysgeusia, meningeal signs (neck stiffness, Kernig's sign, and Brudzinski's sign), Glasgow coma scale, temperature, systolic blood pressure, heart rate, respiratory rate, room air pulsioxymetry, ronchus, whistles, rales), 13 laboratory parameters (C-reactive protein (CRP), creatinine, sodium, potassium, aspartate amino transferase (AST), bilirubin, lactate dehydrogenase (LDH), procalcitonin, hemoglobin, leucocytes, lymphocytes, platelets, D-dimer), and 4 radiological findings in chest X-ray (cardiomegaly, lung interstitial infiltrates, ground-glass opacities, and pleural effusion). For the cases and control group A patients, we also reviewed data from cerebrospinal fluid (CSF) analysis, including glucose, proteins, cells, and microbiological results.

\section{Outcomes}

We defined 4 different outcomes for cases and controls consisting in (1) the need for hospitalization; (2) the need to be admitted to an intensive care unit (ICU); (3) prolonged hospitalization (defined as a length of stay $>7$ days, which is the median length of stay of hospitalized patients in Spain); and (4) in-hospital all-cause mortality.

\section{Statistical analysis}

Discrete variables were expressed as absolute values and percentages, and continuous variables as mean and standard deviation (SD) or median and interquartile range (IQR) if not normally distributed. Incidences were expressed as cases per thousand patients (\%o) with $95 \%$ confidence interval (CI). Differences between case group and controls groups were assessed by the chi-square test (or Fisher exact test if needed) for qualitative variables, and Student's $t$ test (or the MannWhitney non-parametric test if non-normally distributed) for quantitative variables. The magnitude of associations was expressed as unadjusted odds ratio (OR) with 95\%CI (for continuous variables, associations were dichotomized using clinically meaningful cutoffs). As the number of cases expected to be identified was not large, we did not plan to go further in the investigation of the significant relationships identified in the unadjusted analysis by using adjusted models.

In all comparisons, statistical significance was accepted if the $p$ value was $<0.05$ or if $95 \% \mathrm{CI}$ of the risk estimations excluded the value 1 . The analyses were performed with the SPSS (v.24) statistical software package (IBM, Armonk, NY, USA).

\section{Ethics}

The UMC-19 project was approved by the Ethics Committee of the Hospital Clínic of Barcelona (Spain), with the reference number HCB/2020/0534, that acted as the central ethical committee. Under the exceptional circumstances generated by the COVID-19, the urgent need to obtain feasible data related to this new disease, and the non-interventional and retrospective nature of the project, obtainment of written permission from patients to be included in the study was waived. All the patients were codified by investigators of the participating centers before their data were entered into the general database, as patient identity remained anonymous for investigators who analyzed the database. The UMC-19-S 3 was carried out in strict compliance with the Declaration of Helsinki principles. The authors designed the study, gathered and analyzed the data, vouched for the data and analysis, wrote the paper, and decided to publish.

\section{Results}

EDs attended 486,833 patients (average of 131 patients/day/ ED), and 71,904 (14.8\%) were diagnosed with COVID-19. On the other hand, during the pre-COVID phase of the study, 943,205 patients were seen in the ED (average of 253 patients/ day/ED). Patient inclusion in each group is presented in Fig. 1. We identified $29 \mathrm{ME}$ in COVID patients (frequency $=0.40 \%$, $95 \% \mathrm{CI}=0.27-0.58$ ), and these individuals constituted the case 
group. Among the remaining 1,358,134 non-COVID patients attended in EDs, 150 were diagnosed as having ME (frequen$\mathrm{cy}=0.11 \%$, 95\% CI $=0.09-0.13$ ). These patients constituted control group A (non-COVID-ME). In comparison to nonCOVID patients coming to the ED, COVID patients exhibited a significantly higher frequency of $\mathrm{ME}(\mathrm{OR}=3.65$, $95 \% \mathrm{CI}=2.45-5.44)$. On the other hand, control group B was made up of 290 randomly selected COVID patients without ME (COVID-non-ME) during the same period. Infection by SARS-CoV-2 was confirmed by RT-PCR in $48.3 \%$ and $74.8 \%$ of patients in the case group and control group B, respectively $(p=0.002)$. Regarding the diagnosis of COVID patients in the COVID-ME patients with a negative RT-PCR result, this was based on the presence of respiratory symptoms with interstitial lung infiltrates or ground-glass lung opacities in the X-ray or pulmonary CT.

The mean age of the case group was 57.0 (SD 23.1) years and 17 (58.6) were female. The remaining baseline characteristics of these patients are shown in Table 1. Compared to nonCOVID-ME, case group patients more frequently had dyspnea and chest X-ray abnormalities (Tables 1, 2, 3, and 4). Neck stiffness was less frequent in COVID-ME patients that in non-COVID-ME. From the analytical point of view, COVID-ME patients more frequently had increased in CRP,
LDH, and D-dimer levels, and decreased leucocyte and lymphocyte counts. The biochemistry and cell pattern of CFS are described in Table 3, being similar in both groups. Regarding microbiological findings in the CFS, it should be highlighted that after cultures, antigen testing, and multiplex PCR, no microbiological diagnosis was achieved in patients with COVID infection, except one patient who was RT-PCR positive for SARS-CoV-2 in CSF (Table 3).

When we compared cases with control group B patients, we observed that headache (OR 24.7, 95\%CI 10.165-60.149), altered mental status (OR 12.864, 95\%CI 6.615-25.016), neck stiffness (OR 12.154, 95\%CI 8.410-17.564), and vomiting (OR 3.7, 95\% CI 1.353-10.234) were associated with a higher risk of ME in COVID patients. Respiratory symptoms were more frequent in COVID-non-ME patients than in COVID-ME patients (Tables 1, 2, 3, and 4).

Comparing the case group with control group $\mathrm{A}$, the need for hospitalization was present in 28 (96.6\%) COVID-ME patients and in $148(98.7 \%)$ non-COVID-ME patients $(p=0.417)$, while admission to the ICU occurred in 12 (42.9\%) COVID-ME patients and in 39 (26.4\%) nonCOVID-ME patients $(p=0.077)$. In addition, hospitalization longer than 7 days was observed in 13 (44.8\%) COVID-ME patients and in $53(35.3 \%)$ non-COVID-ME patients

Table 1 Baseline characteristics of patients with COVID-19 with meningoencephalitis and comparison with patients without COVID-19 with meningoencephalitis (control group A) and with patients with COVID-19 without meningoencephalitis (control group B).

\begin{tabular}{|c|c|c|c|c|c|}
\hline & $\begin{array}{l}\text { Cases } \\
\text { (COVID-ME) } \\
N=29\end{array}$ & $\begin{array}{l}\text { Control group A } \\
\text { (non-COVID-ME) } \\
N=150\end{array}$ & $\begin{array}{l}\text { Control group B } \\
\text { (COVID-non-ME) N=290 }\end{array}$ & $p$ value 1 & $p$ value 2 \\
\hline \multicolumn{6}{|l|}{ Demographics } \\
\hline Age (years) [median (IQR)] & $63(39-75)$ & $54(32-73)$ & $64(51-77)$ & 0.235 & 0.329 \\
\hline Sex (female) & $17(58.6)$ & $66(44.0)$ & $136(46.9)$ & 0.214 & 0.248 \\
\hline \multicolumn{6}{|l|}{ Comorbidities } \\
\hline Hypertension & $13(44.8)$ & $58(38.7)$ & 135 (46.6) & 0.535 & 0.859 \\
\hline Dyslipidemia & $11(37.9)$ & $42(28.0)$ & $97(33.4)$ & 0.284 & 0.627 \\
\hline Diabetes mellitus & $6(20.7)$ & $37(24.7)$ & $52(17.9)$ & 0.646 & 0.713 \\
\hline Active smoker & $4(13.8)$ & $29(19.3)$ & $20(6.9)$ & 0.460 & 0.355 \\
\hline Asthma & $3(10.3)$ & $7(4.7)$ & $20(6.9)$ & 0.223 & 0.494 \\
\hline Coronary artery disease & $2(6.9)$ & $7(4.7)$ & $22(7.6)$ & 0.615 & 0.893 \\
\hline Obesity (clinically estimated) & $2(6.9)$ & $21(14.0)$ & $45(15.5)$ & 0.295 & 0.212 \\
\hline Chronic kidney disease & $2(6.9)$ & $5(3.3)$ & $19(6.6)$ & 0.365 & 0.943 \\
\hline Immunosuppression & $2(6.9)$ & $7(4.7)$ & $14(4.8)$ & 0.615 & 0.626 \\
\hline Cerebrovascular disease & $1(3.4)$ & $12(8.0)$ & $20(6.9)$ & 0.387 & 0.475 \\
\hline Dementia & $1(3.4)$ & $7(4.7)$ & $25(8.6)$ & 0.771 & 0.332 \\
\hline Active cancer & $1(3.4)$ & $16(10.7)$ & $27(9.3)$ & 0.225 & 0.287 \\
\hline Chronic obstructive pulmonary disease & $0(0)$ & $8(5.3)$ & $26(9.0)$ & 0.203 & 0.092 \\
\hline
\end{tabular}

${ }^{1} p$ values refer to comparison between cases and control group A

${ }^{2} p$ values refer to comparison between cases and control group $\mathrm{B}$

$M E$, meningoencephalitis; $I Q R$, interquartile range 
Table 2 Clinical and analytical characteristics of the acute episode of patients with COVID-19 with meningoencephalitis and comparison with patients without COVID-19 with meningoencephalitis (control group A) and with patients with COVID-19 without meningoencephalitis (control group B)

\begin{tabular}{|c|c|c|c|c|c|}
\hline & $\begin{array}{l}\text { Cases } \\
\text { (COVID-ME) } \\
N=29\end{array}$ & $\begin{array}{l}\text { Control group A } \\
\text { (non-COVID-ME) } \\
N=150\end{array}$ & $\begin{array}{l}\text { Control group B } \\
\text { (COVID-non-ME) } \\
N=290\end{array}$ & $p$ value1 & $p$ value 2 \\
\hline \multicolumn{6}{|l|}{ Symptoms at ED arrival } \\
\hline Lasting symptoms (days) [median (IQR)] & $3(17)$ & $2(1-6)$ & $7(4-10)$ & 0.183 & 0.003 \\
\hline Fever & $18(62.1)$ & $80(53.3)$ & $163(56.2)$ & 0.387 & 0.544 \\
\hline Rhinorrhea & $1(3.4)$ & $9(6.0)$ & $20(6.6)$ & 0.584 & 0.475 \\
\hline Cough & $3(10.3)$ & $5(3.3)$ & $171(59.0)$ & 0.094 & $<0.001$ \\
\hline Expectoration & $1(3.4)$ & $12(8.0)$ & $42(14.5)$ & 0.387 & 0.097 \\
\hline Dyspnea & $7(24.1)$ & $5(3.3)$ & $166(57.2)$ & $<0.001$ & 0.001 \\
\hline Chest pain & $3(10.3)$ & $5(3.3)$ & $38(13.1)$ & 0.094 & 0.672 \\
\hline Abdominal pain & $3(10.3)$ & $5(3.3)$ & $16(5.5)$ & 0.094 & 0.295 \\
\hline Vomiting & $6(20.7)$ & $40(26.7)$ & $19(6.6)$ & 0.500 & 0.007 \\
\hline Diarrhea & $3(10.3)$ & $12(8.0)$ & $50(17.2)$ & 0.677 & 0.341 \\
\hline Altered mental status & $18(62.1)$ & $85(56.7)$ & $18(6.2)$ & 0.590 & $<0.001$ \\
\hline Headache & $12(41.4)$ & $86(57.3)$ & $35(12.1)$ & 0.114 & $<0.001$ \\
\hline Anosmia & $1(3.4)$ & $0(0)$ & $21(7.2)$ & 0.023 & 0.442 \\
\hline Dysgeusia & $0(0)$ & $1(0.7)$ & $22(7.6)$ & 0.659 & 0.124 \\
\hline Seizure & $4((13.8)$ & $17(11.3)$ & $0(0)$ & 0.706 & $<0.001$ \\
\hline Neck stiffness & $3(10.3)$ & $49(32.7)$ & $0(0)$ & 0.015 & $<0.001$ \\
\hline Kernig's sign & $1(3.4)$ & $23(15.3)$ & $0(0)$ & 0.086 & 0.002 \\
\hline Brudzinski’s sign & $1(3.4)$ & $24(16.0)$ & $0(0)$ & 0.074 & 0.002 \\
\hline \multicolumn{6}{|l|}{ Signs at ED arrival [median (IQR)] } \\
\hline Temperature $\left({ }^{\circ} \mathrm{C}\right)$ & $37.3(36.4-37.7)$ & $37.2(36.2-38.0)$ & $36.6(36.0-37.3)$ & 0.822 & 0.010 \\
\hline $\mathrm{SBP}(\mathrm{mmHg})$ & $125(102-143)$ & $131(114-151)$ & $126(113-140)$ & 0.142 & 0.551 \\
\hline Heart rate $(\mathrm{bpm})$ & $100(80-109)$ & $90(78-108)$ & $88(78-100)$ & 0.387 & 0.043 \\
\hline Respiratory rate (bpm) & $18(16-21)$ & $16(14-20)$ & $18(16-23)$ & 0.017 & 0.955 \\
\hline Room air pulsioxymetry $(\%)$ & $96(91-98)$ & $98(95-99)$ & $96(93-98)$ & 0.032 & 0.724 \\
\hline \multicolumn{6}{|l|}{ Laboratory findings [median (IQR)] } \\
\hline C-reactive protein $(\mathrm{mg} / \mathrm{dL})$ & $4.0(1.6-10.9)$ & $1.6(0.4-6.5)$ & $5.9(1.9-12.0)$ & 0.045 & 0.468 \\
\hline Creatinine $(\mathrm{mg} / \mathrm{dL})$ & $0.8(0.7-1.0)$ & $0.8(0.6-1.0)$ & $0.9(0.7-1.1)$ & 0.414 & 0.260 \\
\hline Sodium $(\mathrm{mmol} / \mathrm{L})$ & $138(134-140)$ & $138(135-140)$ & $138(136-140)$ & 0.784 & 0.422 \\
\hline Potassium $(\mathrm{mmol} / \mathrm{L})$ & $3.8(3.6-4.2)$ & $4.0(3.7-4.4)$ & $4.0(3.7-4.4)$ & 0.118 & 0.044 \\
\hline Aspartate amino transferase (IU/L) & $26(17-44)$ & $24(17-36)$ & $30(22-45)$ & 0.425 & 0.203 \\
\hline Bilirubin $(\mathrm{mg} / \mathrm{dL})$ & $0.7(0.4-1.0)$ & $0.5(0.4-0.9)$ & $0.5(0.4-0.7)$ & 0.903 & 0.218 \\
\hline Lactate dehydrogenase (IU/L) & $275(198-483)$ & $207(158-263)$ & $270(205-346)$ & 0.020 & 0.574 \\
\hline Procalcitonin $(\mathrm{ng} / \mathrm{mL})$ & $0.16(0.11-1.06)$ & $0.12(0.06-1.3)$ & $0.10(0.05-0.18)$ & 0.457 & 0.028 \\
\hline Hemoglobin $(g / L)$ & $13(12-15)$ & $13(12-15)$ & $13.8(12.6-14.8)$ & 0.968 & 0.921 \\
\hline Leucocytes count (cells $/ \mu \mathrm{L})$ & $8.7(5.0-11.8)$ & $10.6(7.8-14.6)$ & $6.6(4.9-9.1)$ & 0.008 & 0.191 \\
\hline Lymphocytes & $1.05(0.70-1.67)$ & $1.4(1.0-2.3)$ & $1.1(0.8-1.6)$ & 0.018 & 0.550 \\
\hline Platelets (cells $/ \mu \mathrm{L}$ ) & $203(144-310)$ & $235(182-296)$ & $212(164-263)$ & 0.274 & 0.932 \\
\hline D-dimer (ng/mL) & $898(570-2770)$ & $622(366-1596))$ & $620(360-1272)$ & 0.138 & 0.036 \\
\hline \multicolumn{6}{|l|}{ Chest X-ray } \\
\hline Chest X-ray performed & $25(86.2)$ & $118(78.7)$ & $280(96.6)$ & 0.354 & 0.010 \\
\hline Cardiomegaly & $1(4.0)$ & $16(14.8)$ & $28(10.4)$ & 0.114 & 0.304 \\
\hline Interstitial lung infiltrates & $11(44.0)$ & $7(6.0)$ & $113(40.4)$ & $<0.001$ & 0.772 \\
\hline Ground-glass lung opacities & $10(40.0)$ & $5(4.3)$ & $160(57.1)$ & $<0.001$ & 0.098 \\
\hline Pleural effusion & $2(8.0)$ & $3(2.7)$ & $12(4.4)$ & 0.208 & 0.415 \\
\hline
\end{tabular}

${ }^{1} p$ values refer to comparison between cases and control group A

${ }^{2} p$ values refer to comparison between cases and control group B

$M E$, meningoencephalitis; $I Q R$, interquartile range; $S B P$, systolic blood pressure; $E D$, emergency department

$p$ values in bold denote statistically significant differences $(p<0.05)$

$(p=0.332)$. There were $7(24.1 \%)$ deaths in the COVID-ME patients while there were $16(10.7 \%)$ in non-COVID-ME patients $(p=0.047)$. Regarding comparison of the case group with control group B, the need for hospitalization was present in $28(96.6 \%)$ COVID-ME patients and in 220 (75.9\%)
COVID-non-ME patients $(p=0.011)$, while admission to an ICU was observed in 12 (42.9\%) COVID-ME patients and in $16(7.3 \%)$ COVID-non-ME patients $(p<0.001)$. Hospitalization longer than 7 days was shown in 13 (44.8\%) COVID-ME patients and in 80 (27.6\%) COVID-non-ME 
Table 3 Lumbar puncture and microbiological results of patients with COVID-19 with meningoencephalitis and comparison with patients without COVID-19 with meningoencephalitis (control group A)

\begin{tabular}{|c|c|c|c|}
\hline & $\begin{array}{l}\text { Cases (COVID-ME) } \\
N=29 \\
n(\%)\end{array}$ & $\begin{array}{l}\text { Control group A } \\
\text { (non-COVID-ME) } \\
N=150 \\
n(\%)\end{array}$ & $p$ value \\
\hline \multicolumn{4}{|l|}{ Lumbar puncture } \\
\hline Decreased CSF pressure $\left(<10 \mathrm{H}_{2} \mathrm{O} \mathrm{cm}\right)$ & $1(3.4)$ & $12(8.0)$ & 0.711 \\
\hline Increased CSF pressure $\left(>20 \mathrm{H}_{2} \mathrm{O} \mathrm{cm}\right)$ & $1(3.4)$ & $4(2.7)$ & 0.508 \\
\hline Glucorachia [median (IQR)] & $67(52-84)$ & $63(48-83)$ & 0.306 \\
\hline Proteinorachia [median (IQR)] & $76(44-106)$ & $70(40-132)$ & 0.786 \\
\hline Nucleated cells [median (IQR)] & $51(25-119)$ & $86(20-346)$ & 0.135 \\
\hline Polymorphonuclears [median (IQR)] & $10(4-32)$ & $14(2-85)$ & 0.684 \\
\hline Polymorphonuclear predominance & $9(31.0)$ & $69(46.0)$ & 0.136 \\
\hline Lymphocytes [median (IQR)] & $25(3-68)$ & $20(6-88)$ & 0.821 \\
\hline Lymphocyte predominance & $20(69.0)$ & $81(54.0)$ & 0.136 \\
\hline \multicolumn{4}{|l|}{ Microbiological findings in $\operatorname{CSF}[n(\%)]$} \\
\hline Streptococcus pneumoniae & $0(0)$ & $21(14.0)$ & 0.032 \\
\hline Herpes simplex virus & $0(0)$ & $9(6.0)$ & 0.175 \\
\hline Enteroviruses & $0(0)$ & $5(3.3)$ & 0.318 \\
\hline Mycobacterium tuberculosis & $0(0)$ & $4(2.6)$ & 0.373 \\
\hline Varicella-zoster virus & $0(0)$ & $4(2.6)$ & 0.373 \\
\hline Neisseria meningitidis & $0(0)$ & $3(2.0)$ & 0.442 \\
\hline Haemophilus influenza & $0(0)$ & $3(2.0)$ & 0.442 \\
\hline Listeria monocytogenes & $0(0)$ & $3(2.0)$ & 0.442 \\
\hline Staphylococcus aureus & $0(0)$ & $1(0.7)$ & 0.659 \\
\hline Propionibacterium acnes & $0(0)$ & $1(0.7)$ & 0.659 \\
\hline Epstein barr & $0(0)$ & $1(0.7)$ & 0.659 \\
\hline Streptococcus agalactiae & $0(0)$ & $1(0.7)$ & 0.659 \\
\hline Influenza virus & $0(0)$ & $1(0.7)$ & 0.659 \\
\hline Cryptococcus neoformans & $0(0)$ & $1(0.7)$ & 0.659 \\
\hline Escherichia coli & $0(0)$ & $1(0.7)$ & 0.659 \\
\hline All microbiological tests negative & $29(100)$ & $91(60.6)$ & $<0.001$ \\
\hline \multicolumn{4}{|l|}{ SARS-CoV-2 RT-PCR result in CSF } \\
\hline Positive & $1(3.5)$ & $0(0)$ & 0.022 \\
\hline Negative & $9(31.0)$ & $15(10)$ & 0.002 \\
\hline Not done & $19(65.5)$ & $135(90)$ & $<0.001$ \\
\hline \multicolumn{4}{|l|}{ Final etiological diagnosis of the ME } \\
\hline Bacterial & 0 & 34 & 0.004 \\
\hline Tuberculosis & 0 & 4 & 0.373 \\
\hline Viral (identified) & 1 & 20 & 0.129 \\
\hline Unidentified (presumed bacterial) & $9(32.2)$ & $28(30.7)$ & 0.890 \\
\hline Unidentified (presumed viral) & $19(67.8)$ & $63(69.3)$ & 0.890 \\
\hline
\end{tabular}

$C S F$, cerebrospinal fluid; $M E$, meningoencephalitis; $I Q R$, interquartile range; $R T P C R$, reverse transcriptase polymerase chain reaction

$p$ values in bold denote statistically significant differences $(p<0.05)$ patients $(p=0.051)$, and there were $7(24.1 \%)$ deaths among COVID-ME patients compared to 48 (16.6\%) in COVIDnon-ME patients $(p=0.302)$. Nonetheless, we only detected statistically significant differences in case outcomes with respect to in-hospital mortality, which was higher than in non-COVID-ME patients $(\mathrm{OR}=2.158 ; 95 \% \mathrm{CI}=1.041-$ 4.475). There were also statistically significant differences in the need for hospitalization $(\mathrm{OR}=8.016$; 95\% CI $=1.190$ 
Table 4 Magnitude of statistically significant associations found in the unadjusted analysis

\section{Odds ratio $95 \%$ confidence interval}

Characteristics of meningoencephalitis in COVID patients (respect to meningoencephalitis in non-COVID patients)

$\begin{array}{lll}\text { Ground-glass lung opacities } & 5.600 & 3.090-10.150 \\ \text { Interstitial lung infiltrates } & 5.369 & 2.901-9.937 \\ \text { Dyspnea } & 4.428 & 2.390-8.204 \\ \text { Neck stiffness } & 0.282 & 0.089-0.891\end{array}$

Risk factors in COVID patients to develop meningoencephalitis (respect to COVID patients not developing meningoencephalitis)

$\begin{array}{lll}\text { Headache } & 24.727 & 10.165-60.149 \\ \text { Altered mental status } & 12.864 & 6.615-25.016 \\ \text { Neck stiffness } & 12.154 & 8.410-17.564 \\ \text { Vomiting } & 3.721 & 1.353-10.234\end{array}$

66.672) and admission to an ICU (OR=5.893; 95\% CI=3.117-11.140), which were higher than in COVID-non-ME patients (Fig. 2).

\section{Discussion}

ME is a life-threatening infection associated with substantial mortality and a risk of permanent disability in survivors despite the availability of highly active antibiotics and advances in providing intensive care to critically ill patients [16]. The ME syndrome is not usually observed as a form of COVID presentation, but its incidence is higher than that observed for non-COVID patients. We found that around $0.40 \%$ of COVID patients in the ED had ME. While this incidence, which was determined during a 2-month period of the COVID pandemic, should be considered as low, it is more than 4-fold higher than what is usually seen in non-COVID patients. The epidemiology of ME is highly dependent on geographical factors, the development of society, and the number of preventive interventions, with an incidence of 0.6-4 cases per 100,000 adults/year in developed countries $[17,18]$. In the current report, and taking into account the catchment area of the 61 EDs participating in the UMC-19$\mathrm{S}_{3}$ study (15.2 million inhabitants), the standardized incidence of ME was 3.5 per 100,000 person/year (or 3.0 if we discount ME cases observed in patients with COVID-19). Therefore, these figures are close to those previously reported and reinforce the reliability of the data presented in the UMC$19-\mathrm{S}_{3}$ study and suggest a direct role of SARS-CoV-2 infection in many of the cases of ME seen during the COVID-19 pandemic.

The profile of patients with ME in COVID patients is not different from that of $\mathrm{ME}$ observed in the general population in terms of demographics and comorbidity. Neck stiffness was less frequent in COVID-ME patients that in non-COVID-ME, and there was a tendency to a lower frequency of Kernig's and Brudzinski's signs. Within the context of a pandemic, this fact may hamper the clinical diagnosis of ME and not overlook any finding. The sensitivity of the classic triad of fever, neck stiffness, and altered mental status is low (44\%), but almost all of these patients presented at least two out of the four symptoms - headache, fever, neck stiffness, and altered mental status [19]. Headache, altered metal status, and fever are present with the same frequency in COVID-ME and non-COVIDME. All of these symptoms must make physicians aware of a possible diagnosis of ME even during the pandemic. Actually, although COVID-19 preferentially affects the
Fig. 2 Outcomes of patients with COVID-19 and

meningoencephalitis compared with controls
Odds Ratio ( $95 \% \mathrm{Cl}$ )

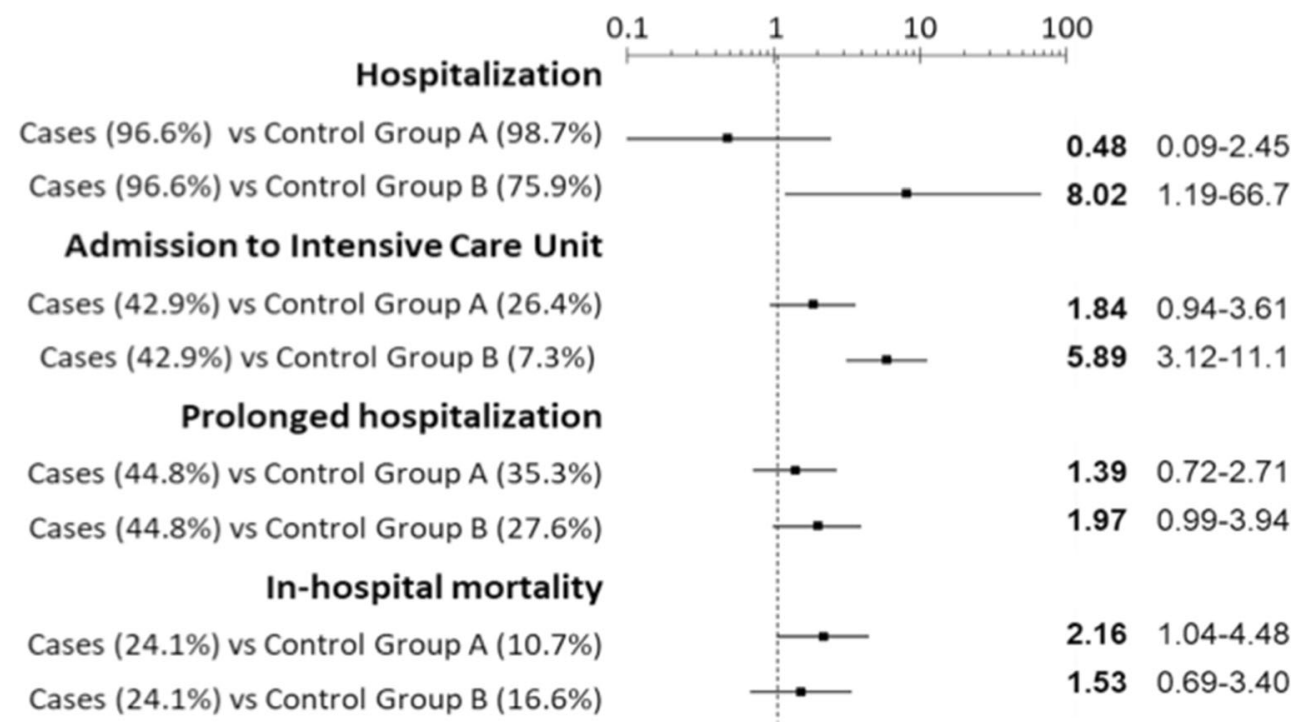


respiratory system, neurological symptoms (such as headache, dizziness, hypogeusia, and neuralgia) and complications (encephalopathy, acute cerebrovascular diseases, impaired consciousness, and skeletal muscular injury) have also been described [1, 5, 20, 21]. Indeed, headache, altered metal status, neck stiffness, and vomiting were associated with a higher risk of ME in COVID patients. Nevertheless, the symptoms described are commonplace in many severe infections and could represent disturbances in neurological function rather than neurological disease per se, and therefore, suspicion of ME is important to begin the diagnostic process.

Coronaviruses are not primarily neurotropic virus, and their primary target is the respiratory epithelium. The target receptor for attachment to cells is through the angiotensin converting enzyme-2 receptor (ACE 2). These receptors are also found in glial cells in the brain and spinal neurons. Hence, it can attach, multiply, and damage neuronal tissue. Some mechanism of brain invasion has been postulated: (1) a retrograde transfer via the olfactory epithelium or through the cribriform bone; (2) disruption of the blood-brain barrier during the viremia phase of illness causing the virus to enter the brain directly; and (3) invasion of peripheral nerve terminals by $\mathrm{CoV}$ which then gains entry to the CNS through the synapse connected route $[1,5,11,20]$. However, the mechanism by which the CNS is affected is still unclear.

CSF detection of coronavirus RNA seems to be infrequent $[22,23]$. Although RT-PCR of CSF was negative/not performed in the majority of patients, the CSF profiles compatible with viral ME, the large screening for usual pathogens with negative results, the temporal association with a COVID diagnosis, and the knowledge that coronaviruses are known for their neurological tropism for inducing encephalitis suggest that SAR-CoV-2 could have been the pathogen responsible for the ME disease in several of our cases. In fact, in one COVID-ME patient, the SARS-CoV-2 antigen was detected in CSF by RT-PCR, demonstrating the invasive capacity of the virus. This is not unexpected, since over a number of years, human coronaviruses including SARS-CoV have been identified as possible pathogens for pathologies outside the respiratory systems $[21,24,25]$. One report showed that SARS-CoV genome sequences were detected by RT-PCR in brains of all SARS autopsies [26].

Several predictors of unfavorable outcome have been described [27]: septic shock, seizures, advanced age, low CSF glucose, low CSF leukocyte count and high protein, systemic compromise, coma, pneumococcal ethiology, high APACHE II score, cranial nerve paresis, high erythrocyte sedimentation rate, absence of fever, and longer interval to treatment. Among these, the more frequent systemic compromise seen in COVID-ME patients could explain the increases in mortality. Case group patients more frequently had dyspnea, chest Xray abnormalities, and higher acute-phase reactants.

\section{Limitations}

This study has several limitations. First, the diagnosis of ME was based on clinical manifestations, lumbar puncture, abnormality on electroencephalography, and CT scan findings, and RT-PCR in CSF was not performed in the majority of patients. However, as explained in the "Discussion" section, a relationship between ME and SARS-CoV-2 is plausible. Second, in about half of the COVID patients with ME, SARS-CoV-2 infection was not demonstrated by RT-PCR nasopharyngeal swab, and diagnosis was based exclusively on clinical findings and the presence of the typical lung parenchymal infiltrates in chest X-ray or pulmonary CT. However, this has been the case in many countries, due to the reagent shortage experienced at the beginning of the pandemic $[28,29]$. Third, as the number of cases was not large, we could not further investigate the significant relationships identified in the unadjusted analysis by using adjusted models. However, ME is a very uncommon disease, and it is very difficult to add cases quickly enough even in a national network to communicate the results during the pandemic. Additionally, a type II error cannot be ruled out due to the limited sample size of our series. Fourth, the retrospective nature of the study could have led to a loss of cases and information in the different sites. Although this information was collected from the electronic databases of the EDs, a possible selection bias cannot be ruled out, and it cannot be ensured that all the possible cases in the different hospitals were collected. Nonetheless, we believe that the results reliably reflect the epidemiology and the characteristics of ME during the COVID pandemic.

\section{Conclusions}

Despite these limitations, we conclude that the incidence of ME in COVID patients attending the ED is low, at about $0.4 \%$, but it is much higher than in the nonCOVID population. This suggests a potential role of SARS-CoV-2 as an additional viral infection causative of ME, which could be responsible for many of the lymphocytic ME cases seen during the pandemic. In fact, the presence of the SARS-CoV-2 antigen was detected in the CSF of one of the patients included in the UMC-19-S 3 . Therefore, the presence of headache, altered mental status, neck stiffness, and vomiting in COVID patients should be a red flag for physicians evaluating COVID patients. The ME-COVID group had an increased risk for in-hospital mortality than non-COVID-ME.

Acknowledgments The SIESTA network is formed by the following researchers and centers (all from Spain): 
Steering Committee:

Òscar Miró, Sònia Jiménez (Hospital Clínic, Barcelona), Juan González del Castillo, Francisco Javier Martín-Sánchez (Hospital Clínico San Carlos, Madrid), Pere Llorens (Hospital General de Alicante), Guillermo Burillo-Putze (Hospital Universitario de Canarias, Tenerife), Alfonso Martín (Hospital Universitario Severo Ochoa de Leganés, Madrid), Pascual Piñera Salmerón (Hospital General Universitario Reina Sofía, Murcia), E. Jorge García Lamberechts (Hospital Clínico San Carlos, Madrid), Javier Jacob (Hospital Universitario de Bellvitge, L'Hospitalet de Llobregat, Barcelona), Aitor Alquézar-Arbé (Hospital de la Santa Creu i Sant Pau, Barcelona).

Participating centers:

1. Hospital Universitario Doctor Peset Aleixandre de Valencia: María Luisa López Grima, Ma Ángeles Juan Gómez.

2. Hospital Universitario y Politécnico La Fe de Valencia: Javier Millán, Leticia Serrano Lázaro.

3. Hospital Universitario General de Alicante: Begoña Espinosa, Francisca Molina.

4. Hospital Clínico Universitario de Valencia: José Noceda.

5. Hospital Arnau de Vilanova de Valencia: María José Cano Cano, Rosa Sorando Serra.

6. Hospital Francesc de Borja de Gandía, Valencia: María José Fortuny Bayarri, Francisco José Salvador Suárez.

7. Hospital General Universitario de Elche, Alicante: Matilde González Tejera.

8. Hospital Marina Baixa de Villajoyosa de Alicante: María Rosales, Ana Panadero Cebrián.

9. Hospital Virgen de los Lirios, Alcoy Alicante: Napoleón Meléndez, Patricia Borrás Albero.

10. Hospital Universitario Vinalopó de Elche (Alicante): Adelaida Mateo Arenas, Tamara Martín Casquero.

11. Hospital Universitario de Torrevieja de Alicante: Rigoberto del Rio, Alba Llario Angel.

12. Hospital LluisAlcanys de Xativa: Carles Pérez García, Pilar Sánchez Amador.

13. Hospital Universitario de La Ribera de Valencia: José Vicente Brasó Aznar, José Luis Ruiz López.

14. Hospital de la Vega Baja Orihuela de Alicante: María Carmen Ponce, Elena Díaz Fernández.

15. Hospital Universitario Sant Joan Alicante: Elena Díaz Fernández

16. Hospital General de Requena de Valencia: Eva Robles Montesinos, Verónica de los Santos.

17. Hospital de Lliria de Valencia: Ana Peiró Gómez, Elena Gonzalo Bellver.

18. Hospital de la Santa Creu i Sant Pau (Barcelona): Juan Antonio Arroyo Diaz, Miguel Rizzi.

19. Hospital Clinic (Barcelona): Carlos Cardozo.

20. Hospital Universitari de Bellvitge de Hospitalet de Llobregat (Barcelona): Irene Cabello-Zamora, Carles Ferré-Losa.

21. Hospital Universitari Germans Trias i Pujol de Badalona (Barcelona): Anna Sales Montufo, Pepe Ferrer Arbaizar.

22. Hospital de Terrassa (Barcelona): Josep Tost.

23. Hospital del Mar (Barcelona): Alfons Aguirre Tejedo, Isabel Cirera Lorenzo.

24. Hospital Universitari Joan XXIII (Tarragona): Anna Palau, Ruth Gaya Tur.
25. Hospital Universitari de Girona Dr. Josep Trueta (Girona): Maria Adroher Muñoz, Ester Soy Ferrer.

26. Hospital Universitari de Vic (Barcelona): Lluís LLauger García.

27. Hospital de Sant Pau i Santa Tecla (Tarragona): Enrique Martín Mojarro, Silvia Flores Quesada.

28. Clinica Sagrada Familia (Barcelona): Arturo Huerta García.

29. Hospital Clínico San Carlos (Madrid): Marcos Fragiel.

30. Hospital Universitario La Paz (Madrid): Ana María Martinez Virto, Rosario Torres Santos Olmo.

31. Hospital Universitario de la Princesa (Madrid): Carmen del Arco Galán, Guillermo Fernández Jiménez.

32. Hospital Universitario Severo Ochoa de Leganés (Madrid): Irene Cabrera Rodrigo, María Cruz Yagüe.

33. Hospital Universitario Rey Juan Carlos (Madrid): Belén Rodríguez Miranda, Alejandra Sánchez Arias.

34. Hospital Universitario del Henares (Madrid): Domingo Lopez Ovejero, Santiago Borrás Natividad.

35. Hospital Universitario de Fuenlabrada (Madrid): María Jesús Domínguez, María Eugenia Barrero Ramos.

36. Hospital Universitario Infanta Cristina de Parla (Madrid): Juan Carlos Reparaz González, Francisco Javier Teigell Muñoz.

37. Hospital Comarcal El Escorial (Madrid): Sara Gayoso Martín, Silvia Ortiz Zamorano.

38. Clínica Universidad Navarra de Madrid: Nieves López-Laguna, María García-Uría.

39. Hospital Universitario de Salamanca: Marta Fuentes de Frutos, Francisco Diego Robledo.

40. Complejo Asistencial Universitario de León: Marta Iglesias Vela, Laura Hernando López.

41. Hospital Universitario de Burgos: María Pilar López Díez.

42. Hospital Universitario Rio Hortega (Valladolid): Raquel Talegón Martín, Jesús Angel Moche Loeri, Daniela Gil Loaiza.

43. Complejo Asistencial de Soria: Fadh Beddar Chaib, Ikram Samira Mohamedi Abdelkader.

44. Hospital Universitario Regional de Málaga: Alberto Núñez Chia, José Ignacio Valero Roldán.

45. Hospital Universitario Juan Ramón Jiménez: María José Marchena González, Eissa Jaloud Saavedra.

46. Hospital Costa del Sol de Marbella: Carmen Agüera Urbano, Elisa Delgado Padial.

47. Hospital Valle de los Pedroches de Pozoblanco (Córdoba): Jorge Pedraza García

48. Hospital Virgen del Rocío de Sevilla: Amparo Fernández de Simón Almela.

49. Complejo Hospitalario Universitario de A Coruña: Ricardo Calvo López.

50. Hospital Universitario Lucus Augusti Lugo: Juan José López Díaz.

51. Complejo Hospitalario Universitario de Vigo. Hospital Álvaro Cunqueiro: Raquel Rodríguez Calveiro.

52. Hospital Universitario General de Albacete: Francisco Javier Lucas-Galan, María Ruiperez Moreno.

53. Hospital Virgen de la Luz (Cuenca): Félix González Martínez, Diana Moya Olmeda.

54. Hospital Nuestra Señora del Prado de Talavera de la Reina (Toledo): Ricardo Juárez.

55. Hospital Universitario de Canarias (Tenerife): Patricia Eiroa Hernandez, José Francisco Fernández Rodríguez. 
56. Hospital Universitario de Gran Canaria Dr. Negrín: José Pavón Monzo, Nayra Cabrera González.

57. Hospital Universitario Central Asturias: Desire María Velarde Herrera, Pablo Herrero Puente.

58. Hospital Universitario de Cabueñes (Gijón): Lorena Arboleya Álvarez, María del Rosario Carrió Hevia.

59. Hospital Clínico Universitario Virgen de la Arrixaca: Eva Quero Motto,Nuria Tomas García.

60. Hospital General Universitario Reina Sofía de Murcia: Natalia Martín Diaz, María Paz Ortega Mercader.

61. Hospital San Pedro de Logroño: Noemí Ruiz de Lobera.

62. Hospital Clínico Universitario Lozano Blesa: Belen Arribas Entrala.

Contribution of authors All the authors discussed the idea and design of study and provided patients. Data analysis and first draft writing were done by JGC, OM, and MF. All authors read this draft and provided insight for the final version. JGC is the guarantor of the paper, taking responsibility for the integrity of the work as a whole, from inception to publication.

\section{Declarations}

Conflict of interest The authors declare no competing interests.

\section{References}

1. Mao L, Jin H, Wang M, Hu Y, Chen S, He Q et al (2020) Neurologic Manifestations of Hospitalized Patients With Coronavirus Disease 2019 in Wuhan. China. JAMA Neurol. 77(6):1-9. https://doi.org/10.1001/jamaneurol.2020.1127

2. Needham EJ, Chou SH, Coles AJ, Menon DK (2020) Neurological Implications of COVID-19 Infections. Neurocrit Care. 32(3):667671. https://doi.org/10.1007/s12028-020-00978-4

3. Huang YH, Jiang D, Huang JT (2020) SARS-CoV-2 Detected in Cerebrospinal Fluid by PCR in a Case of COVID-19 Encephalitis. Brain Behav Immun. S0889-1591(20):30770-30774. https://doi. org/10.1016/j.bbi.2020.05.012

4. Duong L, Xu P, Liu A (2020) Meningoencephalitis without respiratory failure in a young female patient with COVID-19 infection in Downtown Los Angeles, early April 2020. Brain Behav Immun S0889-1591(20):30509-30502. https://doi.org/10.1016/j.bbi.2020. 04.024

5. Ahmad I, Rathore FA (2020) Neurological manifestations and complications of COVID-19: A literature review. J Clin Neurosci. 77:812. https://doi.org/10.1016/j.jocn.2020.05.017

6. Kim JE, Heo JH, Kim HO, Song SH, Park SS, Park TH et al (2017) Neurological Complications during Treatment of Middle East Respiratory Syndrome. J Clin Neurol. 13(3):227-233. https://doi. org/10.3988/jcn.2017.13.3.227

7. Algahtani H, Subahi A, Shirah B (2016) Neurological Complications of Middle East Respiratory Syndrome Coronavirus: A Report of Two Cases and Review of the Literature. Case Rep Neurol Med. 2016:3502683. https://doi.org/ $10.1155 / 2016 / 3502683$

8. Arabi YM, Harthi A, Hussein J, Bouchama A, Johani S, Hajeer AH et al (2015) Severe neurologic syndrome associated with Middle East respiratory syndrome corona virus (MERS-CoV). Infection. 43(4):495-501. https://doi.org/10.1007/s15010-015-0720-y

9. Desforges M, Le Coupanec A, Dubeau P, Bourgouin A, Lajoie L, Dubé M et al (2019) Human Coronaviruses and Other Respiratory
Viruses: Underestimated Opportunistic Pathogens of the Central Nervous System? Viruses. 12(1):14. https://doi.org/10.3390/ v12010014

10. Hung EC, Chim SS, Chan PK, Tong YK, Ng EK, Chiu RW et al (2003) Detection of SARS coronavirus RNA in the cerebrospinal fluid of a patient with severe acute respiratory syndrome. Clin Chem. 49(12):2108-2109. https://doi.org/10.1373/clinchem.2003. 025437

11. Werner C, Scullen T, Mathkour M, Zeoli T, Beighley A, Kilgore MD et al (2020) Neurological Impact of Coronavirus Disease of 2019: Practical Considerations for the Neuroscience Community [published online ahead of print, 2020 May 6]. World Neurosurg. 139:344-354. https://doi.org/10.1016/j.wneu.2020.04.222

12. Miró O, González del Castillo J (2020) Collaboration among Spanish emergency departments to promote research: on the creation of the SIESTA (Spanish Investigators on Emergengy Situations TeAm) retwork and the coordination of the UMC-19 (Unusual Manifestations of COVID-19) macroproject. Emergencias 32:269-277

13. González Del Castillo J, CánoraLebrato J, Zapatero Gaviria A, Barba Martín R, Prados Roa F, Marco MJ (2020) Epidemiapor COVID-19 en Madrid: crónica de un reto. Emergencias. 32:191193

14. Ministry of Health. Spanish Government. Accessed: 1-6-2020. Available at: https://cnecovid.isciii.es/covid19/\#niveles-degravedad.

15. Venkatesan A, Tunkel AR, Bloch KC, Lauring AS, Sejvar J, Bitnun A (2013) et al; International Encephalitis Consortium. Case definitions, diagnostic algorithms, and priorities in encephalitis: consensus statement of the international encephalitis consortium. Clin Infect Dis. 57(8):1114-1128

16. Young N, Thomas M (2018) Meningitis in adults: diagnosis and management. Intern Med J. 48(11):1294-1307. https://doi.org/10. 1111/imj.14102

17. Domingo P, Pomar V, Benito N, Coll P (2013) The changing pattern of bacterial meningitis in adult patients at a large tertiary university hospital in Barcelona, Spain (1982-2010). J Infect. 66(2): 147-154. https://doi.org/10.1016/j.jinf.2012.10.030

18. Brouwer MC, Tunkel AR, van de Beek D (2010) Epidemiology, diagnosis, and antimicrobial treatment of acute bacterial meningitis. Clin Microbiol Rev 23:467e92

19. van de Beek D, de Gans J, Tunkel AR, Wijdicks EF (2006) Community-acquired bacterial meningitis in adults. $\mathrm{N}$ Engl $\mathrm{J}$ Med. 354(1):44-53. https://doi.org/10.1056/NEJMra052116

20. Helms J, Kremer S, Merdji H, Clere-Jehl R, Schenck M, Kummerlen $C$ et al (2020) Neurologic Features in Severe SARSCoV-2 Infection. N Engl J Med. https://doi.org/10.1056/ NEJMc2008597

21. Moriguchi T, Harii N, Goto J, Harada D, Sugawara H, Takamino J et al (2020) A first case of meningitis/encephalitis associated with SARS-Coronavirus-2. Int J Infect Dis. 94:55-58. https://doi.org/10. 1016/j.ijid.2020.03.062

22. Bernard-Valnet R, Pizzarotti B, Anichini A, Demars Y, Russo E, Schmidhauser $\mathrm{M}$ et al (2020) Two patients with acute meningoencephalitis concomitant with SARS-CoV-2 infection. Eur J Neurol. https://doi.org/10.1111/ene.14298

23. Bohmwald K, Galvez NMS, Rios M, Kalergis AM (2018) Neurologic Alterations Due to Respiratory Virus Infections. Front Cell Neurosci. 12:386

24. Gu J, Gong E, Zhang B, Zheng J, Gao Z, Zhong Y et al (2005) Multiple organ infection and the pathogenesis of SARS. J Exp Med. 202(3):415-424. https://doi.org/10.1084/jem.20050828

25. Raj VS, Osterhaus AD, Fouchier RA, Haagmans BL (2014) MERS: emergence of a novel human coronavirus. Curr Opin Virol 5:58-62 
26. Solomon IH, Normandin E, Bhattacharyya S, Mukerji SS, Keller K, Ali AS et al (2020) Neuropathological Features of Covid-19. N Engl J Med. https://doi.org/10.1056/NEJMc2019373

27. Dzupova O, Rozsypal H, Prochazka B, Benes J (2009) Acute bacterial meningitis in adults: predictors of outcome. Scand J Infect Dis. 41(5):348-354

28. Gil-Rodrigo A, Miró O, Piñera P, Burillo-Putze G, Jiménez S, Martín A et al (2020) Analysis of clinical characteristics and outcomes in patients with COVID-19 based on a series of 1000 patients treated in Spanish emergency departments. Emergencias. 32:233-241

29. Martín-Sánchez FJ, González Del Castillo J, Valls Carbó A, López Picado A, Martínez-Valero C, Miranda JD et al (2020) Diagnostic groups and short-term outcomes in suspected COVID-19 cases treated in an emergency department. Emergencias. 32:242-252

Publisher's note Springer Nature remains neutral with regard to jurisdictional claims in published maps and institutional affiliations. 